\title{
The Emergence of Partnership Networks in the Enterprise Application Development Industry: A Global Corporation Perspective
}

\author{
Jens-M. Arndt, Thomas Kude, and Jens Dibbern \\ University of Mannheim, Department of Information Systems I, DE \\ e-mail: jens.arndt|kude|dibbern@uni-mannheim.de
}

\begin{abstract}
Within the IS development industry, incumbent system developers (hubs) are increasingly embracing partnerships with less well established companies acting in specific niches (spokes). This paper seeks to develop a better understanding of the motives for this strategy. Relying on existing work on strategic alliance formation, it is argued that partnering is particularly attractive for hubs if these small companies possess certain capabilities that are difficult to obtain through other arrangements than partnering. Drawing on the literature, three categories of capabilities are identified: the capability to innovate within their niche, the capability to provide a specific functionality that can be integrated with the incumbents' systems, and the capability to address novel markets. These factors are analyzed through a single-case study. The case represents a market leader in the global IS development industry, which fosters a network of smaller partner firms. The study reveals that temporal dynamics between the identified factors exist in these networks. A cyclical partnership model is developed that attempts to explain the life cycle of partnerships within such a network.
\end{abstract}

Keywords: Software Ecosystems, Inter-Organizational IS Development, Process Theory, Interfirm Partnership Formation

\section{Introduction}

The structure of the enterprise application systems development industry has been subject to continuous change. While most early systems had been individually developed by software contractors, pre-packaged systems have come to dominate the past decades [6]. However, the integration in-between these systems has proven to be complex and error-prone [27]. Consequently, the trend observable in the industry has been one of consolidation in that existing systems encompassed ever more functionalities, thus reducing the need for integration across

Please use the following format when citing this chapter:

Arndt, J.-M., Kude, T. and Dibbern, J., 2008, in IFIP International Federation for Information Processing, Volume 274; Advances in Information Systems Research, Education and Practice; David Avison, George M. Kasper, Barbara Pernici, Isabel Ramos, Dewald Roode; (Boston: Springer), pp. 77-88. 
system boundaries [11]. However, currently another paradigm is emerging which potentially reverses this consolidation trend. Fueled by the promise of reduced integration effort through the emergence of service-oriented architectures [17], developers of existing systems are partnering with smaller companies. One of the results of this development is a more intense inter-organizational division of labor, which has already been adopted in many other industries [3], and which has been demanded in the IS context for decades [26]. On the one hand, this division of labor implies that the companies focus on their core competencies, such as a particular software component [38]. On the other hand, these specialized companies have to cooperate with each other in order to ensure that the different parts can be integrated into a coherent system. In order to achieve such a cooperation, a hub-andspoke network has been proposed [33]. In this structure, a core firm inter-connects with all other organizations in a stable network. This central organization takes the role of a platform leader that is assumed to define technologies, markets, strategies, structures, and processes [18].

Contrary to strategic alliances or joint ventures that both imply a certain degree of joint resource deployment, these hub-and-spoke networks can be characterized as loosely coupled systems [31] that rely on a certification of the spokes' solutions by the hub. While the IS industry has widely adopted this loosely coupled structure [28], research is not providing answers to the fundamental questions of why the large software vendors abandon their proven strategy of growing through adding functionalities to their own systems. Drawing on the theory of the duality of inducements and opportunities, it is argued that the issue of why hubs form partnerships is equivalent to the question of which capabilities spokes possess that make them attractive partners for the large companies [1]. Analyzing which capabilities should be considered in this context, three broad categories of spoke capabilities are identified [19]. These are further discussed in the light of this study and integrated into a theoretical framework that guides our empirical analysis.

\section{Theoretical Foundations}

\subsection{Access to Dynamic Capabilities as Inducement for Partnering}

Previous research has predominantly drawn on the resource-based view (RBV) for understanding why organizations enter into cooperative relationships [21]. By viewing firms as bundles of resources, it has been argued that the main reason why firms partner is to gain access to resources which they currently do not possess, but which the partner is offering [15]. This fact has also been labelled as $d u$ ality of inducements and opportunities, indicating that the propensity to form inter-organizational linkages not only depends on the organizations' willingness to overcome resource gaps, but also on a potential partner's attractiveness, i.e. its 
ability to close these gaps [1]. In particular, dynamic capabilities are assumed to increase an organization's attractiveness. Dynamic capabilities refer to the ability of using resources in a way that enables organizations not only to react to changes in their environment, but to shape it to a certain extent [39]. This ability is particularly relevant in dynamic contexts, such as systems development [30]. Therefore, in order to understand the underlying rationale for the hubs to enter into a partnership with a spoke, it is essential to examine the unique dynamic capabilities that the spokes bring into the network. Dynamic capabilities as success factors for small software firms have been analyzed previously [25]. However, we argue that these dynamic capabilities not only enhance a small software firm's performance, but also increase its attractiveness as a partner for hub organizations.

According to a large scale survey, network formation in high-tech industries such as software development is motivated by three types of capabilities: Speeding the process of innovation, accessing complementary technology, and accessing novel markets [19]. As this study explicitly takes the hubs' perspective, subsequently aspects of these three broad categories are developed that the spokes are assumed to possess and the hubs are assumed to lack. These are proposed as key motivating factors for a hub to enter into partnerships with spokes.

\subsubsection{Capabilities to Develop Modular Innovations}

Innovativeness plays a key role for organizations in high-tech industries such as the software industry, since they have to constantly cope with new technological advances as well as changing customer requirements [12]. However, while innovativeness clearly constitutes one of the key dynamic capabilities of software firms [25], it is less clear how a hub can benefit from the innovativeness of its small partners. More clarity is achieved through classifying innovations into different categories. As such, for industries that are characterized by a high degree of modularity, the distinction can be made between innovation at the component and the architectural level [20]. While component innovations accrue within the boundaries of specific modules, architectural innovations affect the way or the general structure by which the components are bound together to form a coherent system. In this context, it can be assumed that it is the responsibility of the spokes to engage in these component innovations. This ongoing modular innovativeness of spokes improves the overall system through improving its components.

Another classification divides innovation into being either sustaining or disruptive [7]. Sustaining innovations improve existing products in a way that is valued by mainstream customers, mostly through adding functionality. Contrary, disruptive innovations first appear to be simpler, cheaper or with lower quality than existing products, but might eventually threaten the incumbent products' market position. Within the modular system of the IS industry, spoke companies, on the one hand, provide sustainable innovations by simply adding functionality to the overall system. On the other hand, according to [7], disruptive innovations are most 
likely to happen in small, flexible companies that serve specific market niches. Thus, by partnering with spokes, hubs ensure that their network disposes of the capability to benefit from and keep control over disruptive innovations.

The reason why smaller firms are assumed to have higher innovative capabilities can be seen in their entrepreneurial potential. Both concepts are closely intertwined in that the main characteristic of an entrepreneur is assumed to be innovativeness [4, 14]. However, there is no inevitable connection between entrepreneurial spirit and innovation. Entrepreneurs as profit-seeking individuals are expected to suppress their propensity to innovate if facing adverse conditions [4]. These adverse conditions are supposed to be especially present in large organizations. In contrast, small organizations are assumed to be more suitable for stimulating entrepreneurial spirit. This perception is also shared by [30], who argue that creating value through innovation is best achieved by tapping into the entrepreneurial potential of a network of self-managed firms. Thus, the following relationship is proposed between innovativeness of spokes and their attractiveness as partners.

Proposition I. Large IS producers (hubs) are partnering with small software developers (spokes) in order to gain access to their capabilities to develop modular innovations.

\subsubsection{Capabilities to Provide Niche Functionalities}

As it has been mentioned above, a key goal of enterprise IS is the coverage of all information flows within an organization. However, IS have to be considered an intellectual rather than an industrial technology [24]. Thus, they are not constrained by physical aspects, but only by the imagination of their users, and therefore IS can be used in a virtually unlimited number of possible domains [8]. Consequently, it is impossible for any single organization, regardless of its size, to cover all these possible domains. A potential, yet limited, way to overcome this drawback is the abundant opportunity to customize standardized IS in order to adapt them to specific customer needs [36]. The here proposed network structure goes beyond this, in that it enables spokes to augment the general purpose platform developed by the hubs with certain complementary niche solutions [2]. The platform thus takes advantage of the mass-marketability of a standardized system, while the specialized components take advantage of the individualized solution quality of bespoke systems [37].

The concept of network externalities indicates that the platform of a central vendor becomes more valuable if more complementary products exist. Hence, complementary solutions are a key necessity for establishing a successful platform. By tying many of these specific niche functionalities to a hub's platform, this platform becomes more attractive for customers, which in turn attracts more partners to the network. A positive feedback loop is initiated, which ideally results in this hub's platform becoming a de facto standard [32]. Thus, the spokes' capabilities to provide attractive niche functionalities is considered a key motive for 
hubs to engage in partnerships. Especially those solutions that have a proven track record in the markets and that are complementary to the hub's offering promise to fall into this category. This leads us to the following second proposition.

Proposition F. Large IS producers (hubs) are partnering with small software producers (spokes) in order to gain access to their capabilities to provide complementary niche functionalities.

\subsubsection{Capabilities to Access Novel Markets}

The final aspect that is promising to be a prime reason for hubs to partner with spokes in such an inter-organizational network is the ability to address novel markets. The existing enterprise IS have been developed out of the striving for seamless integration of information flows in large corporations [11]. In this market segment, they have been highly successful, so that today the market is more and more saturated. Most large corporations either already possess an enterprise IS, or deliberately decided not to implement one [16]. Therefore, the vendors of these systems have to address new markets in order to sustain the growth rates they achieved in the past. Considering the fact that in the past, large IS vendors were selling their systems to the narrow market segment of global corporations, there are still ample opportunities to improve the systems' adequacy for specific requirements of other customer groups [34]. However, as these IS developers are by definition large corporations themselves, they incur considerable overhead costs for addressing these requirements. Thus, depending on the size of a potential market, these large vendors might decide not to develop specific solutions for this market. Contrary, based on the hub's platform, highly focused and efficient niche players are able to develop solutions for markets that the large hubs consider unattractive. Through the joining of forces between the two groups, the overall integrated solution can thus be used in broader markets, benefiting both hubs and spokes.

Another aspect of these niche IS developers is the fact that they can be assumed to have a much closer relationship to their customers, which is assumed to be a key success factor for IS development [35]. It has even been argued that users of these enterprise IS should form a strategic relationship with their developers in order to benefit from seamless future interaction [5]. The reason for this can again be seen in the fact that the customer to a considerable extent depends on the recommendations of the developer, and thus a good relationship between them is imperative for success. As these relationships require considerable time to emerge since they are causally ambiguous and socially complex in that they depend on the people involved in the relationship [23], these also classify for being a key capability of spokes that the hubs attempt to access. Therefore, the following proposition summarizes this market objective from the hubs' perspective.

Proposition M. Large IS producers (hubs) are partnering with small software producers (spokes) in order to gain access to their capabilities to address narrow markets. 


\subsection{An Integrated Framework for Partnership Formation}

The preceding discussion has evolved around the research objective of developing capabilities that act as inducements for joining partnerships in the IS development industry. Three broad factors were identified and refined in the here proposed inter-organizational IS development context. As such, benefits from the spokes' modular innovation capabilities, their capabilities to provide niche functionalities, and their capabilities to access novel markets have been identified. The proposed relationships are illustrated in Figure 1.

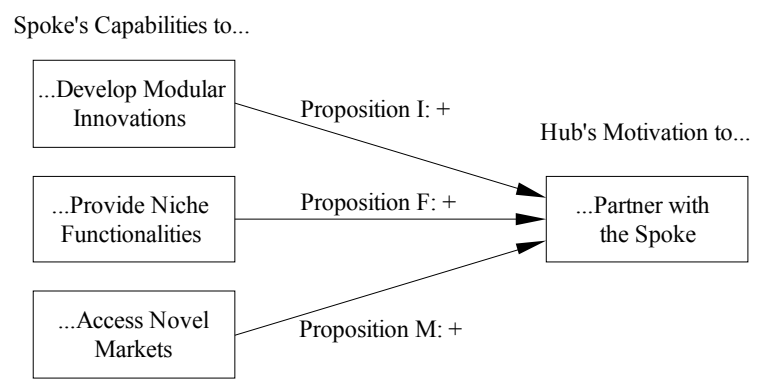

Fig. 1 A Model for Explaining the Partnering Motives of Large Corporations.

\section{Empirical Analysis}

\subsection{Methodology and Data Collection}

According to [22], the choice of an appropriate research design is to a large extend determined by the research question that is intended to be answered. This paper deals with the question why global IS development corporations are partnering with small organizations. According to [41], the case study approach is particularly promising to answer such why questions about motivations and rationales. As the IS development industry is characterized by an oligopolistic structure, the number of potential cases is limited. However, each one of these large IS development companies can be considered a unique case that is worth being analyzed in detail [41]. Consequently, a single-case study design was chosen [29]. This approach allows for an in-depth investigation of partnership formation, with special consideration of the contextual conditions of this organization [41].

The selected case very well meets the requirements of such a single-case study. The company has a proven track record of developing standardized enterprise IS for over thirty years. With thousands of customers in over one hundred countries 
worldwide it can be characterized as a truly global company. Finally, with multibillion dollar revenues, it is one of the leading organizations in IS development. In this case company, several interviews were conducted during spring and summer 2007. Overall, sixteen professionals from various positions in the organization were interviewed in a semi-structured fashion. On average, the interviews lasted about one hour and resulted in a total verbatim transcript of 180 pages with close to 110,000 words. In addition to these interviews, data was collected from multiple other sources, such as secondary material and personal observation. Although the expert interviews were guided by the propositions presented in Section 2, the character of our analysis is rather exploratory.

For data analysis purpose, codes were developed for the three discussed propositions by assigning a brief label for each of them: Innovation, Functionality, and Market [29]. Using this scheme the transcripts of the interviews were then coded by assigning text passages to the three partnership motives proposed in the theoretical framework. These extracted interview fragments were then used for a twostage analysis. First, a rough estimate of the importance of each of the proposed benefits was assessed by counting the frequencies of the relevant fragments [29]. Then, a second round of analysis was conducted in which the underlying background of each fragment was carefully considered in light of each proposition [13]. In the following, the findings from this two-staged process will be presented.

\subsection{Data Analysis}

Table 1 provides an overview of the number of relevant interview fragments for each of the proposed partnership motives. As can be inferred from this table, good support was found for all of the proposed motives. The spokes' capabilities to open up new markets for the hubs were most often mentioned as a reason for partnering. From the two other aspects, the capabilities to develop modular innovations seemed to be the second most important. Finally, the capability to provide niche functionalities was mentioned least often. Overall, however, all three were mentioned regularly, giving good support for the proposed assumptions of their importance.

\begin{tabular}{|l|c|c|c|}
\hline & Innovation & Functionality & Market \\
\hline Total & 39 & 31 & 47 \\
\hline Average & 2.60 & 2.07 & 3.13 \\
\hline
\end{tabular}

Table 1 Relevant Interview Fragments for each Capability

A closer examination of the content of the interview quotes largely confirmed the picture obtained from the frequency counting. Especially the capabilities of 
spokes to react to customer needs and to establish a good relationship to them was mentioned by the interviewees in the case. Moreover, the large hub corporation was not inclined to address all specific niche markets. Rather, it deliberately decided to partner with small companies in order to provide the necessary solutions for these contexts. Closely related to this broader market reach is the hub's second motive of adding niche functionalities to its platform. Indeed, the choice not to cover all possible domains of an IS was a deliberate one by the hub. Especially for those functionalities that were tightly integrated with other technologies, such as certain machinery, or for those for which a well established de-facto standard existed, partnering was considered attractive. Thus, ample support was found for the proposition that complementary functionalities are motivating partnership formation. Finally, access to innovative capabilities was seen as a main impetus for forming partnerships. Indeed, the hub realized the need for a new innovation model. The interview partners acknowledged that by restricting the sources of innovation to its own organization, the hub would fall behind. By virtue of their smaller size, spoke companies were found to possess the agility and flexibility that the hub was unable to realize. The entrepreneurial spirit of the spokes was deemed necessary to successfully pursue innovative ideas at the modular level.

\section{A Process Model of Partnership Formation}

The previous section has revealed that all three proposed motives play an important role in the hub's decision to partner. However, further analysis of the data shows that not all motives are equally important for all partners. Rather, different kinds of partnerships can be identified: Some partners are loosely attached to the network, others are tightly connected; some partnerships exist only for a brief time span, others are long lasting. Studying these differences reveals that the static perspective only insufficiently explains the underlying patterns of network formation. Rather, partnerships between hub and spokes go through various stages, which are characterized by these differences in the cooperation. In this context, the above discussed three motives may not only be viewed as drivers for network formation, but also as events that trigger the transition between the stages in this developmental sequence [40].

Essentially, our process model closely resembles the one proposed by [10], who argue that cooperations between hospitals evolve through emergence, transition, maturity, and critical crossroads. Translated to hub-and-spoke networks in the IS development industry, we find five stages that are traversed throughout the process of partnership formation: (0) the initial stage, (1) the awareness stage, (2) the partnership formation and integration stage, (3) the joint market access stage, and (4) the re-evaluation stage, where the partnership can take alternative trajectories from continuation to ending. In the initial stage, both hub and spoke operate independently, developing innovative solutions. This is followed by the awareness 
stage where hub and spoke become aware of each other's innovations. At this point, it is important to note that innovations of the spokes are perceived as being attractive if they represent existing software solutions that are already sold in the market, rather than concepts or ideas that may potentially become innovations. While in the awareness stage, hub and spoke may build an informal relationship, the next stage is the partnership formation and integration stage, where the hub formally certifies the technical integration capability of the spoke's solution with the hub platform. This requires cooperation between hub and spoke personnel on a technical level. Once solution integration is officially ensured, the next stage is joint market elaboration and access of hub and spoke. This joint addressing of markets is considered a recurring event that ensures the ongoing cooperation between the involved partners. Since the final goal of the hub is revenue generation, innovative ideas not only have to be turned into software solutions that are compatible with the hub platform; they have to be turned into integrated, marketable software solutions. Thus, once joined market campaigns are initiated, this leads to the final, ongoing stage, where the success of the partnership is evaluated. This may result in two trajectories. First, the partnership may continue. Second, the hub may decide to take over the functionality of the spoke by either integrating the spoke organization or substituting its solution.

We found the choice between these two trajectories to be dependent on the type of alignment between hub and spoke solution. While we assumed that the hub was looking primarily for complementary functionalities, we also found evidence that the hub was partnering with spokes that were providing supplementary functionalities (i.e., similar functionalities brought into the relationship) [9]. As it has been discussed above, the case company had a well developed understanding of what was part of its solution portfolio and what was assumed to be developed by partners. Thus, the parts that were intentionally developed by partners, such as infrastructure components, were indeed complementary. For these, partnership relations were found to be rather stable in that partners were allowed to pursue their own developments.

The large hub was found to also partner with those small companies that were offering functionalities that the case company considered to be within the scope of its system, mainly business functionalities. However, this was only the case for functionalities not covered by any actual solution of the large company. We term this constellation latent supplementary or temporary complementarity. In such a situation, the partner was providing a solution that the case company was actually willing to provide itself, however, had so far been unable to, for whatever reasons. Those partners had similarly fruitful relationships with the case company as those that provided infinitely complementary functionalities. The situation was found to be entirely different, however, if the small spoke partners provided supplementary functionalities. These were indeed allowed to partner if customers actually demanded their specific niche functionalities. However, these relationships were not found to be very stable. Indeed, the case company actively attempted to integrate these functionalities into its own system. 
To sum up, it can be argued that the partnership process is a cyclic one. It starts with an innovation that is developed by a partner. Once it becomes clear that this innovation is attractive for customers, it is technically integrated with the platform of the case company. This integrated solution is then expected to be successfully sold in the market. Once this market success is achieved, the next step depends on the nature of the partner's solution. If it is an infrastructure or niche solution, the partnership continuous to exist as long as it is successful in the market and the solution stays in its niche. If the large hub, however, decides that the solution is supposed to become part of the platform, it either develops its own solution that imitates the functionalities of the existing partner solution, or it outrightly acquires the partner organization. If a partner company's management wants to stay independent, it is then required to come up with a new innovation, and the process begins anew. The overall structure of this partnership process is illustrated in Figure 2 .

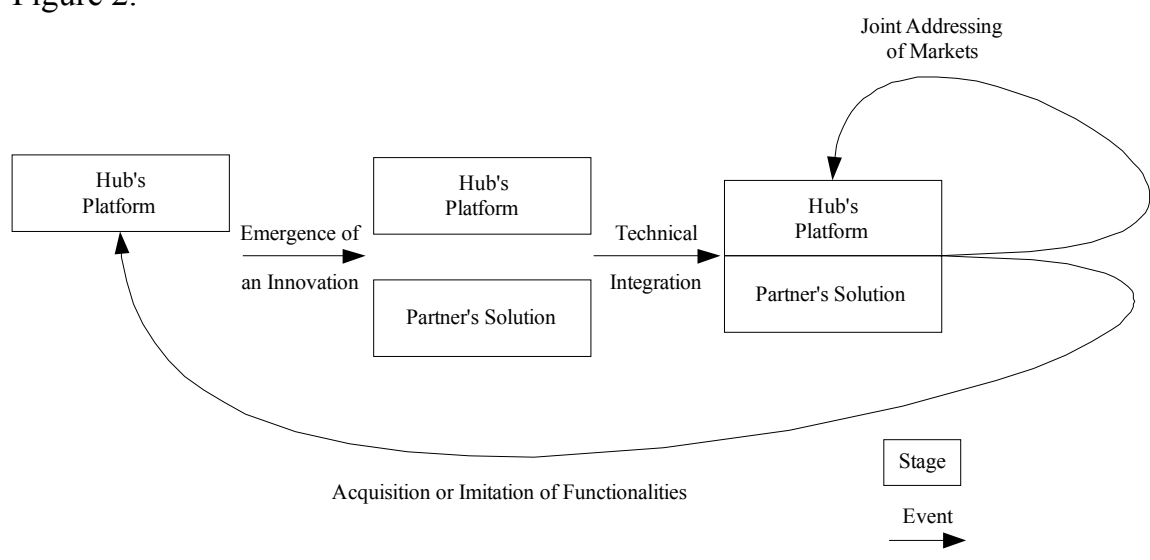

Fig. 2 The Innovation Cycle in IS Development Networks.

\section{Conclusions}

This paper addressed the question why large IS development companies not only join but even actively foster IS development networks. Drawing from the perspective of the duality of inducements and opportunities, spokes' capabilities were analyzed which were assumed to make them attractive partners for the hubs. Three of these were theoretically developed and further analyzed in a case study of one large IS developer. In this case, indeed all three aspects were found to be important. However, it also became obvious throughout this case that the reasons for this strategy cannot be fully understood from a variance theory perspective. Rather, the entire life cycle of such a partnership has to be examined. A model of 
this life cycle starts with an innovation of a spoke company, which is then integrated with the overall system, and finally successfully brought to market.

However, what has also been found is that IS development differs from traditional manufacturing in that these relationships are not necessarily stable. Rather, the distinction between complementary and supplementary functionalities has been introduced in order to differentiate those partnerships that are indeed stable from those that are not. Moreover, the novel concept of temporal complementarities has been introduced. These are functionalities that are currently complementary, but which over time can be assumed to turn into supplementarities. Partners that provide such solutions were found to be engaged in an innovation race, which forces them to come up with a novel solution before the hub acquires them or, even worse, imitates their solution.

\section{References}

1. Ahuja, G.: The Duality of Collaboration: Inducements and Opportunities in the Formation of Interfirm Linkages. Strategic Management Journal 21(3), 317 - 343 (2000)

2. Arndt, J.M., Dibbern, J.: The Tension between Integration and Fragmentation in a Component-Based Software Development Ecosystem. In: R.H. Sprague Jr. (ed.) Proc. of the 39th HICSS. IEEE Computer Society, Washington (2006)

3. Baldwin, C.Y., Clark, K.B.: Design Rules - Volume 1. The Power of Modularity. The MIT Press, Cambridge (2000)

4. Baumol, W.J.: The Free-Market Innovation Machine - Analyzing the Growth Miracle of Capitalism. Princeton University Press, Princeton (2002)

5. Butler, J.: Risk Management Skills Needed in a Packaged Software Environment. Information Systems Management 16(3), 15 - 20 (1999)

6. Campbell-Kelly, M.: From Airline Reservation to Sonic the Hedgehog: A History of the Software Industry. The MIT Press, Cambridge (2003)

7. Christensen, C.: The Innovator's Dilemma: When New Technologies Cause Great Firms to Fail. Harvard Business School Press, Boston (1997)

8. Curley, K.F., Pyburn, P.J.: "Intellectual” Technologies: The Key to Improving White-Collar Productivity. Sloan Management Review 24(1), 31 - 39 (1982)

9. Das, T.K., Teng, B.S.: A Resource-Based Theory of Strategic Alliances. Journal of Management 26(1), $31-61$ (2000)

10. D'Aunno, T., Zuckerman, H.: A Life-Cycle Model of Organizational Federations: The Case of Hospitals. The Academy of Management Review 12(3), 534 - 545 (1987)

11. Davenport, T.H.: Putting the Enterprise into the Enterprise System. Harvard Business Review 76(4), 121 - 131 (1998)

12. Denning, P.J.: The Social Life of Innovation. Communications of the ACM 47(4), 15 - 19 (2004)

13. Dibbern, J., Winkler, J., Heinzl, A.: Explaining Variations in Client Extra Costs between Software Projects Offshored to India. MIS Quarterly 31 (Special Issue on IS Offshoring forthcoming) (2008)

14. Drucker, P.F.: Innovation and Entrepreneurship, Butterworth Heinemann, Oxford (1994)

15. Eisenhardt, K.M., Schoonhoven, C.B.: Resource-based View of Strategic Alliance Formation: Strategic and Social Effects in Entrepreneurial Firms. Organization Science 7(2), $136-$ 150 (1996) 
16. von Everdingen, Y., van Hillegersberg, J.,Waarts, E.: ERP Adoption by European Midsize Companies. Communication of the ACM 43(3), 27 - 31 (2000)

17. Fan, M., Stallaert, J., Whinston, A.B.: The Adoption and Design Methodologies of Component-Based Enterprise Systems. European Journal of Information Systems 9(1), 25 - 35 (2000)

18. Gawer, A., Cusumano, M.A.: Platform Leadership. Harvard Business School Press, Cambridge (2002)

19. Hagedoorn, J.: Understanding the Rationale of Strategic Technology Partnering: Interorganizational Modes of Cooperation and Sectoral Differences. Strategic Management Journal 14(5), $371-385$ (1993)

20. Henderson, R.M., Clark, K.B.: Architectural Innovation: The Reconfiguration of Existing Product Technologies and the Failure of Established Firms. Administrative Science Quarterly 35 (Special Issue: Technology, Organizations, and Innovation), 9 - 30 (1990)

21. Ireland, R.D., Hitt, M.A., Vaidyanath, D.: Alliance Management as a Source of Competitive Advantage. Journal of Management 28(3), 413 - 446 (2002)

22. Kerlinger, F.N., Lee, H.B.: Foundations of Behavioral Research, 4th ed., Harcourt College Publishers, Fort Worth (2000)

23. Kumar, K., van Dissel, H.G., Bielli, P.: The Merchant of Prato - Revisited: Toward a Third Rationale of Information Systems. MIS Quarterly 22(2), 199 - 226 (1998)

24. Lee, A.S.: Researching MIS. Oxford University Press, Oxford (1999)

25. Mathiassen, L.,Vainio, A.M.: Dynamic Capabilities in Small Software Firms: A Sense-andRespond Approach. IEEE TEM 54(3), 522 - 538 (2007)

26. McIlroy, M.D.: Mass Produced Software Components. In: Naur, P., Randell, B. (eds.) Software Engineering, pp. 138 - 156. NATO Science Committee, Garmisch (1969)

27. Mertens, P.: Integrierte Informationsverarbeitung 1, 15th ed., Gabler, Wiesbaden (2005)

28. Messerschmitt, D.G., Szyperski, C.: Software Ecosystem - Understanding an Indispensable Technology and Industry. The MIT Press, Cambridge (2003)

29. Miles, M.B., Huberman, A.M.: Qualitative Data Analysis. Sage, Thousand Oaks (1994)

30. Miles, R.E., Miles, G., Snow, C.C.: Collaborative Entrepreneurship - How Communities of Networked Firms Use Continuous Innovation to Create Economic Wealth. Stanford Business Books, Stanford (2005)

31. Orton, J.D.,Weick, K.E.: Loosely coupled systems: A Reconceptualization. Academy of Management Review 15(2), 203 - 223 (1990)

32. Shapiro, C., Varian, H.R.: Information Rules - A Strategic Guide to the Network Economy. Harvard Business School Press, Boston (1999)

33. Snow, C.C., Miles, R.E., Coleman, H.J.: Managing 21st Century Network Organizations. Organizational Dynamics 20(3), 4 - 20 (1992)

34. Soh, C., Kien, S.S., Tay-Yap, J.: Cultural Fits and Misfits: Is ERP a Universal Solution? Communications of the ACM 43(4), 47 - 51 (2000)

35. Somers, T.M., Nelson, K.G.: A Taxonomy of Players and Activities across the ERP Project Life Cycle. Information and Management 41(3), 257 - 278 (2004)

36. Sommerville, I.: Software Engineering, 7th ed., Pearson Education Limited, Harlow (2004)

37. Sprott, D.: Componentizing the Enterprise Application Packages. Communications of the ACM 43(4), $63-69$ (2000)

38. Staudenmayer, N., Tripsas, M., Tucci, C.L.: Interfirm Modularity and its Implications for Product Development. Journal of Product Innovation Management 22(4), 303 - 321 (2005)

39. Teece, D.J., Pisano, G., Shuen, A.: Dynamic Capabilities and Strategic Management. Strategic Management Journal 18(7), 509 - 533 (1997)

40. van de Ven, A.H.: Suggestions for Studying Strategy Process: A Research Note. Strategic Management Journal 13 (Special Issue: Strategy Process: Managing Corporate SelfRenewal), 169 - 191 (1992)

41. Yin, R.K.: Case Study Research - Design and Methods, Applied Social Research Methods Series, vol. 5, 3rd ed., Sage, Thousand Oaks (2003) 